\title{
Multivariate factor analysis (MFA) approach to evaluate the quality of stored Cavendish banana sourced from different geographical areas
}

\author{
Nicole Roberta Giuggioli*, Cristiana Peano, Thais Mendes Da Silva \\ Department of Agricultural, Forest and Food Sciences (DISAFA), University of Turin, Largo Paolo Braccini, 2, Grugliasco (TO) 10095, \\ Piedmont, Italy
}

\section{A B S TR A C T}

\begin{abstract}
The Multiple Factor Analysis (MFA) was applied to assess deterioration patterns and evaluate quality stability of bananas samples with 5 different origins. Quality evaluation (weight loss, dry matter, colour, total soluble solids, texture and nutraceutical analysis) was conducted at $21^{\circ} \mathrm{C}$ for up to 12 days of storage time. Ecuador samples retained a better colour and firmer texture during shelf life while Cameroon samples demonstrated very poor quality for almost all quality indicators. Although MFA showed a similar shelf life pattern for all banana samples, it was possible to observe a greater quality retention of Ecuador samples, represented by higher score values at dimension 1 than other samples. Even though there were significant differences of nutraceutical values during shelf life, the MFA contribution plot demonstrated that nutraceutical quality was not a good indicator of deterioration among the samples, especially with texture and colour parameters.
\end{abstract}

Keywords: Attributes; Banana; Consumption; Origin; Storage

\section{INTRODUCTION}

Objective analysis and better understanding of deterioration drivers from fruit with different origins are needed in order to improve quality and manage the product's shelf life. It has been demonstrated how multivariate approaches, such as the Principle Components Analysis (PCA), enables the detection of complex deterioration patterns in fruit and vegetable products that may not be highlighted with univariate statistics on single data analysis. In previous studies, the use of PCA enabled the assessment ofdifferent trends based on growing regions and cultivar (Finnegan and Beirne et al., 2015a). However, the PCA approach relies on its property of describing differences in data according only to only one theme (a single set of active variables), which in the case of horticultural product's quality assessments means to group data of very heterogeneous nature, such as colour and texture. The Multiple Factor Analysis (MFA) is an extension of PCA, with the advantage of handling different weighted sets of variables collected from the same samples (Gambetta et al., 2017, Hervé et al., 2013). With the MFA approach, data derived from multicomponent attributes, such as texture, nutraceutical, sensorial, colour and flavour, can be grouped in different sets of variables, which are then weighted in order to balance their influence (Lassoued et al., 2008). This concept is in line with the complex nature of fruit quality which is a combination of several variables and consumer behaviour, which may not focus their attention on a set of specific attributes and left others behind. Instead they integrate all the descriptors of the product to reach a global consensus and take a decision (Esteban et al., 2013). MFA also demonstrates the relationship between the set of variables and their common space. Thus, it provides ways of evaluating quality at the single variable level and at the global level, allowing the user to formulate new questions about the data, which may focus on single parameters (e.g.: brix) or on multiple parameters that complement each other to represent a global attribute (e.g.: texture). Currently, MFA is mainly used in sensory studies due to its property of handling different types of data such as continuous or categoric variables (Pagès, 2005). However, it has been

\footnotetext{
*Corresponding author:

Nicole Roberta Giuggioli, Department of Agricultural, Forest and Food Sciences (DISAFA), University of Turin, Largo Paolo Braccini, 2, Grugliasco (TO) 10095, Piedmont, Italy. Telephone: +39 0116708548. Fax: +39 0116708646. E-mail: nicole.giuggioli@unito.it
}

Received: 23 June 2019; Accepted: 27 February 2020 
suggested as a proper approach to many types of quality assessment that involves multi-structured parameters in pre-harvest and postharvest longitudinal studies (Mendes da Silva et al., 2019; Mendes da Silva et al., 2020).

In literature, banana's quality assessment differs considering the factors that are investigated, but most studies focused on the Cavendish variety, which has become a standard on the global market because of its bigger and heavier bunches (Ding et al., 2007) and better resistance to physiopathology (Thakker et al., 2011). Considering the type of attributes that are investigated, peel colour may not necessarily indicate the quality or ripening stage of product since pulp and peel differ in their rate of ripening with respect to temperature (Nyanjage et al., 2001)., Thus, different quality attributes must be determined inaddition to colour, such as, nutraceutic, and texture, which are also influential to consumer's decision and shelf life (Tsamo et al., 2014). Moreover, geographical location, growing practices and ripening process, which are extremely dictated by the market destination (Nannyonga et al., 2016), might affect storage stability in different ways. Therefore, the goal ofthis study was to evaluate Cavendish bananas from five different geographical origins under different quality attributes in order to highlight differences in the ripening pattern. MFA was used to track deterioration patterns during shelf life and to identify sets of variables that best describe freshness of samples.

\section{MATERIALS AND METHODS}

\section{Fruit samples and storage conditions}

A total of 54 Cavendish bananas from Ecuador (E), Colombia (C), Costa Rica (R), Cameron (CM), and Dominican Republic (RD) were provided by the Battaglio S.p.a. warehouse (Piedmont, Italy). Among all the bananas, only Dominican bananas were cultivated and managed under organic conditions. All fruits were previously subjected to artificial ripening with ethylene, according to Battaglio S.p.a. standard protocols, and packaged in cardboard boxes to be sent to the Department of Agricultural, Forest and Food Sciences (DISAFA) at the University of Turin. The fruit then underwent between $3 \frac{1}{2}-4$ colour stages, in compliance with the USDA standard plate. The termination of storage at low temperatures $\left(13^{\circ} \mathrm{C}\right)$ is essential as prolonged low temperature storage was found to impede the sensory quality in terms of texture due to abnormal ripening (Chauhan et al., 2006). In this study, each geographical origin had the samples stored at $21^{\circ} \mathrm{C}$ (T1) in open plastic boxes in order to assess shelf life deterioration under thermal abuse conditions. Temperature was monitored using a data logger. Samples were stored up to 12 days and submitted to quality analysis every 3 days, totalling 4 control steps named "start", "3 d", "6 d", "9 d" and "12 d".

\section{Physical and chemical analysis}

Weight loss of 6 fruits for each time point was determined with an electronic scale (Kern \& Sohn Gmbh) ( $\pm 0.001 \mathrm{~g}$ ) at day 0 (a) and every $3 \mathrm{~d}$ (b). The $\%$ of weight loss was calculated as:

$$
\text { Weight loss }=\frac{\mathrm{a}-\mathrm{b}}{\mathrm{a}} \times 100
$$

Dry matter at $100^{\circ} \mathrm{C}$ to constant weight was determined by cutting slices of $0,5 \mathrm{~mm}$ thickness of 6 replicates for each time point. The fruit dry matter was calculated as a final percentage of the initial wet weight of the slices. Colour was measured in 6 replicates for each time point using a Minolta Chromameter CR-400 (Konica Minolta Sensing inc., Osaka, Japan) on sample peels according to the Commission International d'Eclairage (CIE) L*a*b* system. $L^{*}$ refers to the lightness and ranged from $L^{*}=0$ (black) to $L^{*}=100$ (white) (Bicho et al., 2013). Negative and positive values of $a^{*}$ indicates green and red colour, respectively, while positive and negative $b^{*}$ indicate yellow and blue colour, respectively. Total soluble solids (TSS) with a digital refractometer (Pal 1- Atago) and total acidity (TA) with an automatic titrator (TRITALABAT 1000 series, Hach) were performed for each time point using 3 replicates of filtered and centrifugated juice obtained from 6 fruits with $0.1 \mathrm{~N} \mathrm{NaOH}$ to $\mathrm{pH} 8.1$ and expressed as $\mathrm{g} / 100 \mathrm{~g}$ of citric acid, as described in the OECD guidelines (2009). Texture profile analysis (TPA) was performed for each time point with a texture analyser (TA.XT. plus, Stable Micro Systems) with 6 peeled and cut fruits of $0,5 \mathrm{~mm}$ thick using a $75 \mathrm{~mm}$ plunger. A trigger force of $5 \mathrm{~g}$ and a $30 \%$ of deformation were set, where velocity of pre-test was $2 \mathrm{~mm} / \mathrm{s}$. Both test and post-test velocity were $1 \mathrm{~mm} / \mathrm{s}$. As in Aday et al. (2013) work, the following parameters from the resulting force-time curve were registered: hardness, springiness, cohesiveness, adhesiveness, gumminess and resilience. Additionally, nutraceutical analyses were performed. Total polyphenol content (TPC) was measured according to Folin-Ciocalteu assay (Slinkard and Singleton, 1977) reading the absorbance at $760 \mathrm{~nm}$ by using a spectrophotometer (UV-1600 PC, VWR). The antioxidant capacity (AC) was determined by Ferric Reducing/Antioxidant Power (FRAP) essay, developed by Benzie and Strain (1996). All nutraceutical analyses were performed in triplicate.

\section{Statistical analysis}

Data were analysed through analysis of variance (ANOVA) using the software IBM-SPSS 22 (2015) and averages were separated by Tuckey HSD test $(\mathrm{P}<0,05)$. A Multiple Factor Analysis (MFA) was performed in order to evaluate 
deterioration patterns of samples, thus grouping data by quality attributes. The analysis was performed on in response to 15 different variables grouped to new sets of continuous data named "colour", "texture", "nutraceutical" and "others". The pre-processing step is a crucial part of the analysis (Abdi et al., 2007). In this work, all set of variables were scaled to account for the fact that they could have different variances as a consequence of their different measurement types (Mendes da Silva et al., 2020). One supplementary and qualitative variable named "storage time" was added to obtain centroids by period of shelf life. Supplementary variables have no influence on MFA dimensions, rather they are used to help with interpretation of analyses (Mendes da Silva et al., 2019). Ellipses confident intervals at a 0,05 level of significance were calculated in order to evaluate if there were significant global differences between categories of qualitative variables, thus, between periods of shelf life. As MFA is applied as the PCA of the grand data table, the usual PCA indices can be computed to identify the important components, observations, and variables (Pages, 2005). Thus, a scree plot was produced in order to decide how many dimensions should be kept in the model, and scores and loadings were determined. In addition, some indices specific to MFA, such as partial plots, were also calculated in order to investigate the importance of each table in the common solution.

\section{RESULTS AND DISCUSSION}

From Anova results, all samples were subjected to weight loss, while dry matter decreased during shelf life (data not shown). The cumulative weight loss increased progressively from $0 \%$ on day 1 to an average of $28 \%$ at T 1 conditions by the $12^{\text {th }}$ day of storage when the fruit had become senescent. Water loss is surely the main cause of weight loss, which might also cause a reduction in firmness (Turner, 2001). The maximum permitted levels for weight loss of horticultural products have been reported to be not more than $10 \%$ (Adi et al., 2019). Therefore, the high weight loss observed for all samples by after " $6 \mathrm{~d}$ " in T1 conditions could have an adverse impact on the saleable value of the fruit. Decrease of dry matter was probably related to water migration from peel to pulp and to the breakdown of starch into sugars, which releases moisture in the pulp (Adi et al., 2019).Colour from all samples altered from green to yellow during the first 6 days and then became dark by the end of shelf life (Fig. 1), however, differences were observed between samples. At day "start", L* values (Fig. 2) were initially higher for Ecuador and Cameroon samples while. at the end of shelf life, Cameroon samples kept the highest values. However, it can be observed that Ecuador samples retained higher L* values for a longer period when compared to other samples. The $\mathrm{L}^{*}$ parameter is usually associated with brightness of peel (Pathare et al., 2013). Products that are freshly harvested tend to have a brighter peel, therefore, it is a desirable attribute. During the postharvest period, brightness of peel is known to be greatly reduced with water loss and can be affected by storage conditions, such as very low temperatures, making fruit to develop a dull surface colour (Pathare et al., 2013, Hewage et al., 1996). Thus, Ecuador pre and postharvest practices were probablymore appropriate to preserve brightness of peel. Trends of $\mathrm{L}^{*}$ and $\mathrm{b}^{*}$ values are probably also related to the breakdown of chlorophyll during storage (Opara et al., 2013), followed by yellowing of the peel due to xanthophyll and carotene appearance (Ward and Nussinovitch, 1996) to finally conclude with darkening of the peel due to enzymatic browning reactions. Bananas are prone to undergo browning after de-greening as a result of tissue disruption during storage andthe presence of oxidative enzymes near to chloroplast's structures (Huang et al., 2013). A greater antioxidant capacity could promote a better colour retention of products, however, antioxidant compounds are also prone to undergo enzymatic browning

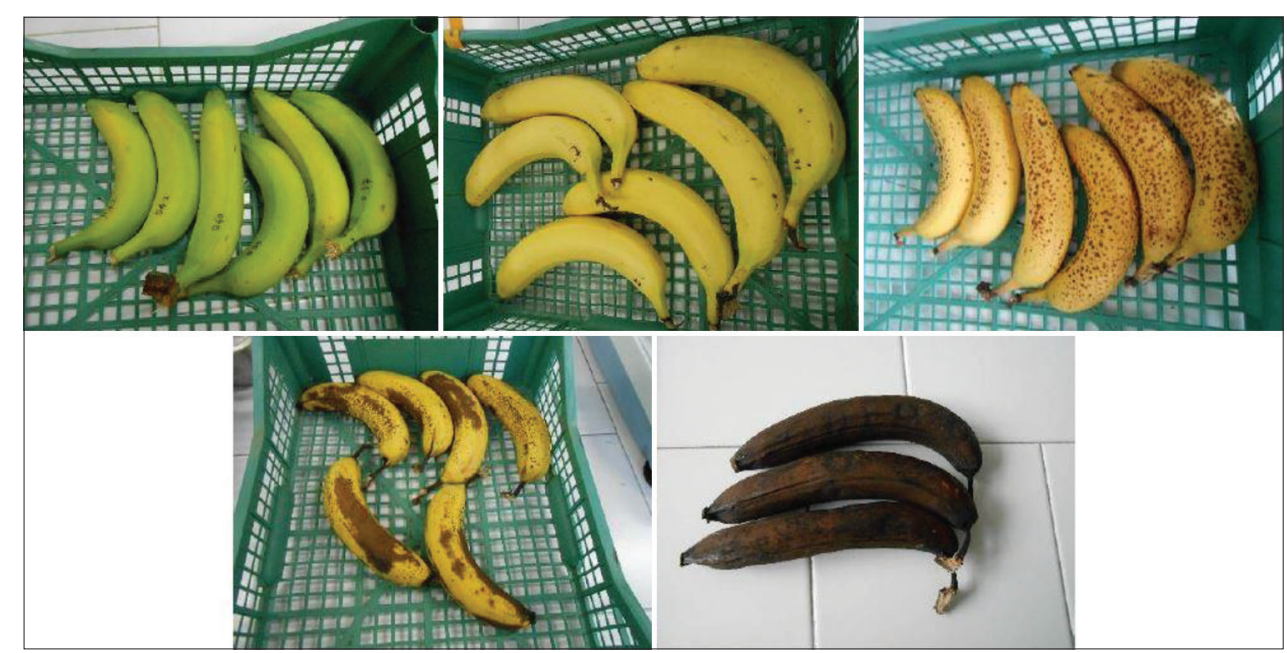

Fig 1. Pictures of Cameroon samples at day $3^{\text {rd }}$, day $6^{\text {th }}$, day $9^{\text {th }}$ and day $12^{\text {th }}$. 
(Pathare et al., 2013). Therefore, the higher amount of antioxidant substances in the Ecuador samples could have led to a higher decrease of $\mathrm{L}^{*}$ values compared to Cameroon samples on T1 conditions. Total soluble solids (TSS) values (Table 1) increased for all samples, with Ecuador and Dominican's bananas presenting the highest values during almost all shelf life period. TSS values were higher, especially after " $3 \mathrm{~d}$ " and "6 $\mathrm{d}$ " when the fruit hasn't yet reached the overripe stage. These results were similar to previous studies (Opara et al., 2013; Rajkumar et al., 2012) and are related to the degradation of starch content of fruit, which is hydrolysed into soluble sugars, such as glucose, sucrose and fructose (Sanaeifar et al., 2016). As the fruit ripens, the increase in the sugar contents of the pulp results in a change in osmotic pressure which causes movement of moisture from the peel into the pulp (Adi et al., 2019), which could explain the dilution of TSS values in all samples after "6 d". Acidity values (data not shown) increased at the overripe stage for all samples. Ecuador bananas in particular presented lower values at the end of shelf life. Acidity in bananas is mostly represented by ascorbic acid, citric acid, malic acid and oxalic acid (Anyasi et al., 2015). Both citric and malic acids are the most important contributors in the end of product's shelf life (Taiti et al., 2015).

\section{Texture analysis}

Changes of texture parameters can be attributed to the structural changes in bananas. This is due to solubilization of pectic material binding the tissue system and retaining the integrity (Chauhan et al., 2006). Only texture attributes that showed significant differences within samples are presented in this study (Table 2). Hardness decreased for all samples. Cameroon and Colombian bananas were the softest samples. Ecuador and Dominican samples kept higher values throughout storage time. Softening of fruit is caused by different phenomena, including loss of cell turgor related to tissue dehydration, cell wall and starch degradation. The latter has the most impact factor due to its massive reduction from $25 \%$ in green bananas to $1-2 \%$ in the overripe stage (Turner, 2001). Adhesiveness is an important parameter for fruit products since it can indicate how sticky products may become (Nishinari and Fang, 2018). Adhesiveness values of samples during storage at T1 conditions enhanced to become closer to 0 , indicating a lower sensation of stickiness of samples at the end of shelf life. No significant differences were detected between samples. Decrease of adhesiveness values wereobserved in strawberry trials and was attributed to the softening of fruit (Caner et al., 2008). Bananas have the tendency to be sticky due to its mucilaginous nature which increases during ripening (Pranita et al., 2014). However, in this study, the opposite trend was observed, probably due to the massive softening of pulp. Gumminess is a combination of both hardness and cohesion parameters. It is identified as the energy required to disintegrate a semi-solid material to a state ready for swallowing (Giuggioli et al., 2018). Similar

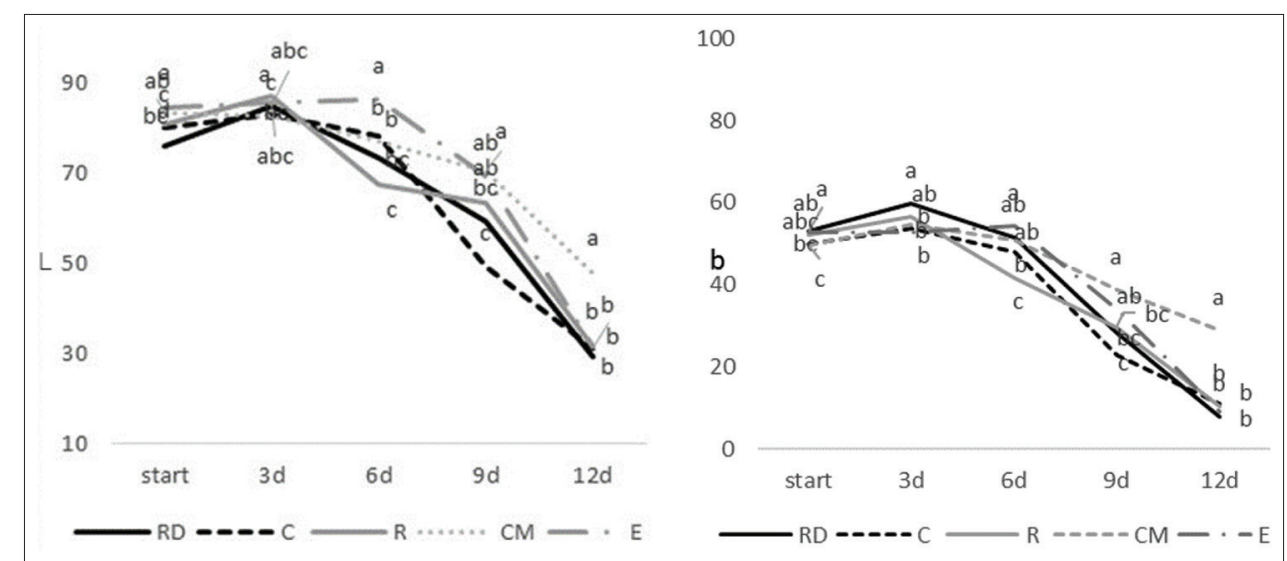

Fig 2. Luminosity $\left(\mathrm{L}^{*}\right)$ and colour $\mathrm{b}^{*}$ values of Republic Dominican, Colombian, Costa Rica, Cameroon and Ecuador samples at $\mathrm{T} 1$ (21 $\left.{ }^{\circ} \mathrm{C}\right)$ storage condition.

Table 1:Total soluble solids ( ${ }^{\circ}$ Brix) values of Republic Dominican, Colombian, Costa Rica, Cameroon and Ecuador samples at T1 $\left(21^{\circ} \mathrm{C}\right)$ storage conditions

\begin{tabular}{lccccc}
\hline Samples & Start & $\mathbf{3 d}$ & $\mathbf{6 ~ d}$ & $\mathbf{9} \mathbf{d}$ & $\mathbf{1 2} \mathbf{d}$ \\
\hline$R D$ & $15,90 \pm 0,46^{\mathrm{c} 1 \mathrm{~A} 2}$ & $22,53 \pm 1,42^{\mathrm{abA}}$ & $23,07 \pm 0,15^{\mathrm{aA}}$ & $23,13 \pm 0,23^{\mathrm{aB}}$ & $20,93 \pm 0,42^{\mathrm{bA}}$ \\
C & $15,16 \pm 0,35^{\mathrm{dAB}}$ & $22,00 \pm 0,20^{\mathrm{aA}}$ & $20,13 \pm 0,06^{\mathrm{bC}}$ & $21,70 \pm 0,46^{\mathrm{aC}}$ & $18,47 \pm 0,42^{\mathrm{cB}}$ \\
$R$ & $11,83 \pm 0,35^{\mathrm{dD}}$ & $21,60 \pm 0,10^{\mathrm{bA}}$ & $22,83 \pm 0,46^{\mathrm{aAB}}$ & $21,83 \pm 0,15^{\mathrm{bC}}$ & $20,50 \pm 0,30^{\mathrm{cA}}$ \\
CM & $14,23 \pm 0,12^{\mathrm{cC}}$ & $22,03 \pm 2,22^{\mathrm{aA}}$ & $22,10 \pm 0,17^{\mathrm{aB}}$ & $19,73 \pm 0,12^{\mathrm{abD}}$ & $18,80 \pm 0,53^{\mathrm{bB}}$ \\
E & $14,36 \pm 0,31^{\mathrm{BBC}}$ & $23,23 \pm 0,47^{\mathrm{aA}}$ & $22,77 \pm 0,60^{\mathrm{abAB}}$ & $24,10 \pm 0,17^{\mathrm{aA}}$ & $21,37 \pm 1,01^{\mathrm{bA}}$ \\
\hline
\end{tabular}

${ }^{1}$ Different minor letters ${ }^{(a-c)}$ in the same row show significant differences $(P \leq 0.05)$ within samples. ${ }^{2}$ Different capital letter ${ }^{(A-D)}$ in the same column show significant differences among treatments $(P \leq 0.05)$ for each storage time 
to hardness, solubilisation of pectin material in the middle lamellae of the fruit resulted in a decrease of cohesiveness (Giuggioli et al., 2018). Thus, gumminess was expected to decrease for all samples. Among all samples, Cameroon bananas presented the lowest values. Therefore, all texture parameters indicate that Cameroon samples were the least suited product for long-term storage.

\section{Nutraceutical compounds}

Bananas have high amounts of polyphenols, especially in the peel, which might present superior antioxidant capacity up to 5 times more than pulp. Among phenols, tannins are considered very important since they might cause an unpleasant taste by enhancing astringency. During the ripening stage, astringency is reduced due to tannins degradation to other phenol compounds (Kiyoshi and Tanimura, 2003). In this study, total polyphenol content
(TPC) values (Fig. 3) increased during shelf life for all samples, with exception of Costa Rica and Dominican samples that remained stable when compared to day "start" in both temperature conditions. It is important to note the variability of Costa Rica samples after " 6 d" might have influenced the detection of a significant increase after "12 d". This is probably because not all fruit from this sample presented the same number of browning spots (ripening stage), leading to fluctuation of TPC values within the sample. Water loss would have led to a concentration of all compounds presented in samples (Suna et al., 2014). The antioxidants in bananas are phenolics, carotenoids and ascorbic acid (Singh et al., 2016). At the end of shelf life, in this study, all samples presented same or greater amounts of antioxidant capacity (AC) values when compared to day "start", with the exception of Dominican samples. Moreover, the Dominican samples were the only ones

Table 2: Hardness, Adhesiveness and Gumminess values of Republic Dominican, Colombian, Costa Rica, Cameroon and Ecuador samples at $\mathrm{T} 1\left(21^{\circ} \mathrm{C}\right)$ storage conditions

\begin{tabular}{|c|c|c|c|c|c|c|}
\hline Texture parameters & Samples & Start & $3 d$ & $6 d$ & $9 d$ & $12 \mathrm{~d}$ \\
\hline \multirow[t]{5}{*}{ Hardness } & $\mathrm{RD}$ & $4593,8 \pm 178,1^{\mathrm{aB}}$ & $3321,7 \pm 315,9^{\mathrm{bBC}}$ & $2481,3 \pm 806,1^{\mathrm{bA}}$ & $1291,5 \pm 66,6^{\mathrm{cB}}$ & $1004,4 \pm 116,2^{\mathrm{cA}}$ \\
\hline & C & $5350,2 \pm 208,3^{\mathrm{aAB}}$ & $3971,9 \pm 328,8^{\mathrm{bAB}}$ & $2499,7 \pm 341,2^{\mathrm{cA}}$ & $2060,1 \pm 69,8^{\mathrm{cA}}$ & $534,6 \pm 55,6^{\mathrm{dB}}$ \\
\hline & $\mathrm{R}$ & $7068,1 \pm 681,7^{\mathrm{aA}}$ & $3342,1 \pm 405,4^{\mathrm{bBC}}$ & $3368,2 \pm 142,4^{\mathrm{bA}}$ & $1818,7 \pm 253,5^{\mathrm{CAB}}$ & $891,4 \pm 101,7^{\mathrm{cA}}$ \\
\hline & $\mathrm{CM}$ & $6415,5 \pm 484,3^{\mathrm{aAB}}$ & $3091,9 \pm 137,2^{\mathrm{bc}}$ & $2632,7 \pm 322,5^{\mathrm{bA}}$ & $566,4 \pm 108,3^{c c}$ & $429,7 \pm 24,1^{\mathrm{cB}}$ \\
\hline & $E$ & $6911,3 \pm 1433,4^{\mathrm{aA}}$ & $4441,0 \pm 172,0^{\mathrm{bA}}$ & $3351,2 \pm 740,7^{\mathrm{bcA}}$ & $2329,9 \pm 343,9^{\mathrm{cdA}}$ & $910,9 \pm 168,9^{\mathrm{dA}}$ \\
\hline \multirow[t]{5}{*}{ Adhesiveness } & $\mathrm{RD}$ & $-174,8 \pm 22,8^{\mathrm{bA}}$ & $-120,2 \pm 29,8^{\mathrm{abA}}$ & $-108,0 \pm 47,7^{\mathrm{abA}}$ & $-77,3 \pm 20,7^{\mathrm{aA}}$ & $-80,5 \pm 15,5^{\mathrm{aA}}$ \\
\hline & $\mathrm{C}$ & $-224,7 \pm 11,9^{\mathrm{bA}}$ & $-193,0 \pm 48,9^{\mathrm{bA}}$ & $-101,2 \pm 19,5^{\mathrm{aA}}$ & $-98,4 \pm 23,4^{\mathrm{aA}}$ & $-96,7 \pm 39,9^{\mathrm{aA}}$ \\
\hline & $\mathrm{R}$ & $-219,2 \pm 4,6^{\mathrm{bA}}$ & $-123,1 \pm 42,5^{\mathrm{bA}}$ & $-155,2 \pm 41,4^{\mathrm{abA}}$ & $-84,8 \pm 7,5^{\mathrm{aA}}$ & $-89,4 \pm 44,5^{\mathrm{aA}}$ \\
\hline & $\mathrm{CM}$ & $-196,3 \pm 14,2^{\mathrm{bA}}$ & $-125,3 \pm 36,9^{\mathrm{abA}}$ & $-112,9 \pm 35,9^{\mathrm{aA}}$ & $-117,7 \pm 39,8^{\mathrm{abA}}$ & $-108,1 \pm 15,7^{\mathrm{aA}}$ \\
\hline & $E$ & $-153,5 \pm 75,5^{\mathrm{aA}}$ & $-155,0 \pm 11,9^{\mathrm{aA}}$ & $-146,1 \pm 48,9^{\mathrm{aA}}$ & $-105,0 \pm 47,0^{\mathrm{aA}}$ & $-95,0 \pm 42,1^{\mathrm{aA}}$ \\
\hline \multirow[t]{5}{*}{ Gumminess } & $\mathrm{RD}$ & $894,6 \pm 140,6^{\mathrm{ac}}$ & $1069,1 \pm 75,8^{\mathrm{aB}}$ & $785,9 \pm 238,9^{\mathrm{abB}}$ & $523,0 \pm 21,8^{\mathrm{bcB}}$ & $383,8 \pm 24,9^{\mathrm{cA}}$ \\
\hline & C & $1023,1 \pm 138,0^{\mathrm{abBC}}$ & $1230,4 \pm 80,3^{\mathrm{aB}}$ & $824,4 \pm 104,9^{\mathrm{bAB}}$ & $777,7 \pm 28,5^{\mathrm{bA}}$ & $277,4 \pm 98,8^{\mathrm{CAB}}$ \\
\hline & $\mathrm{R}$ & $1284,5 \pm 111,5^{\mathrm{aAB}}$ & $1033,6 \pm 52,5^{\mathrm{bB}}$ & $1199,5 \pm 76,6^{\mathrm{abA}}$ & $776,0 \pm 87,3^{\mathrm{cA}}$ & $401,8 \pm 36,8^{d A}$ \\
\hline & $\mathrm{CM}$ & $1136,6 \pm 52,1^{\mathrm{aBC}}$ & $980,9 \pm 113,5^{\mathrm{abB}}$ & $940,4 \pm 40,4^{\text {БАВ }}$ & $266,9 \pm 42,8^{\mathrm{cc}}$ & $198,2 \pm 7,7^{\text {св }}$ \\
\hline & E & $1490,8 \pm 107,8^{\mathrm{aA}}$ & $1520,0 \pm 152,1^{\mathrm{aA}}$ & $1134,7 \pm 154,9^{\mathrm{bAB}}$ & $841,1 \pm 158,4^{\mathrm{bA}}$ & $413,6 \pm 43,6^{\mathrm{cA}}$ \\
\hline
\end{tabular}

${ }^{1}$ Different minor letters ${ }^{(a-d)}$ in the same row show significant differences $(P \leq 0.05)$ within samples. ${ }^{2}$ Different capital letters ${ }^{(A-C)}$ in the same column show significant differences among treatments $(P \leq 0.05)$ for each storage time.

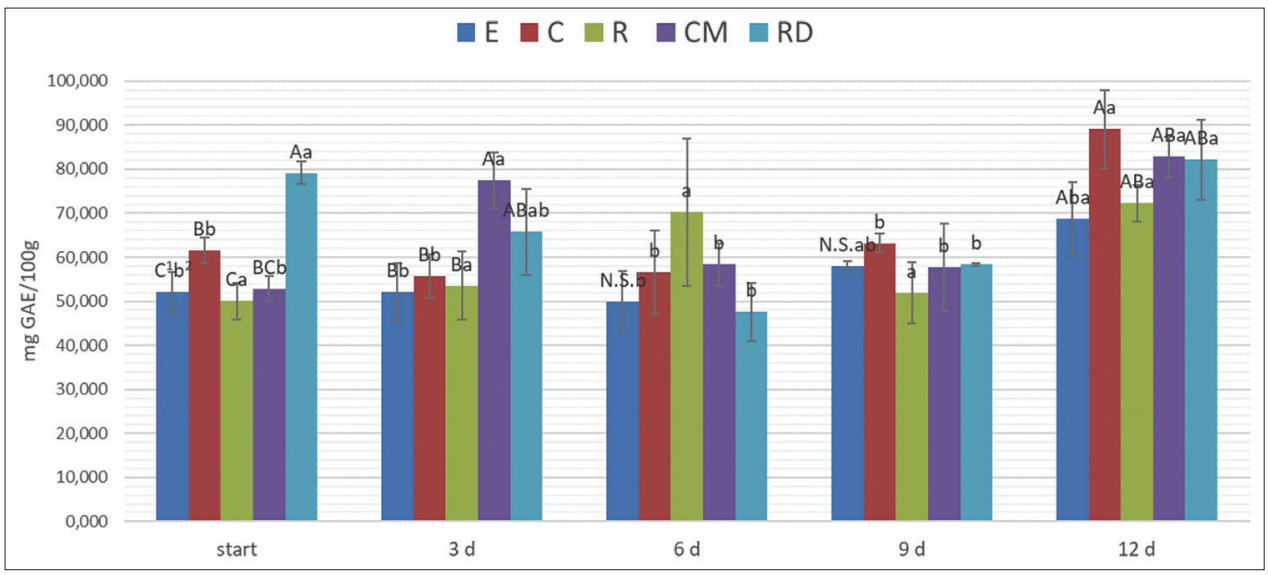

Fig 3. Total polyphenol content values of Republic Dominican, Colombian, Costa Rica, Cameroon and Ecuador samples at $\mathrm{T} 1\left(21^{\circ} \mathrm{C}\right)$ storage conditions. 
with decreased values despite initial higher $\mathrm{AC}$ values when compared to other samples (Fig. 4). Dominican bananas, which came from organic production, presented higher TPC and AC values at day "start" than all the other samples. The higher levels of phenolic compounds in organic crops have been attributed to the soil organic matter. Organic soils are known to have higher microbial biomass and activity, higher biodiversity and more biogeochemical processes. Moreover, higher levels of phenolic compounds in organic agriculture seems to also be related to defence mechanisms in crops against diseases and pests (Johansson et al., 2014). However, superior TPC and AC content of organic production is debatable. Many research trials comparing conventional and organic fruit products have shown contradictory results, with several authors concluding that there is no significant difference between crop systems with respect to TPC and AC content, while others have claimed that significant differences between organic and biodynamic products exist (Johansson et al., 2014). Dominican bananas scarcely retained AC content, while TPC content remained stable. These results suggest that other antioxidant compounds might have undergone browning, such as ascorbic acid. Ascorbic acid is strongly affected by temperature but may incur browning reactions even at room temperature (Patel et al., 2013).

\section{Multivariate factor analysis (MFA)}

The existence of large correlation coefficients between variables or set of variables suggests that those variables could be measuring aspects from the same dimensions. By reducing the dataset with dimensions, ordinations techniques, such as Multivariate Factor Analysis (MFA) and Principle Components Analysis (PCA), achieve the goal of explaining a maximum amount of variance using a small number of constructs called components in PCA or dimensions in MFA analysis. Only the first two dimensions accounted for most of all meaningful variance, accounting for $68,8 \%$ of total variance explained (Fig. 5A). The first dimension presented almost $60 \%$ of total variance explained and it showed a higher correlation's coefficient with supplementary variable "storage time" than dimension 2 . Supplementary variables do not influence dimensions, they only help with interpretation of theMFA analysis. Therefore, it suggests that storage time was best described by the first dimension of MFA. Unlike PCA, loadings from MFA can be squared and variations over squared loadings from each variable are summed up to obtain the contribution of a data set. Thus, contributions are used to evaluate the importance of a data set to a common solution and their relationships (Abdi et al., 2007; Hervé et al., 2013). The plot in Fig. 5B demonstrated how texture and colour, followed by parameters grouped in others, had the largest contribution to describe deterioration patterns, In Fig. 5C, at the level of a single variable it can be observed that all texture and colorimetric parameters were well described by the first dimension, meaning that those were good indicators of sample's deterioration pattern during shelf life. Among the parameters grouped as "others", weight loss, acidity and dry matter were also considered as good indicators of quality evolution since they presented a significant correlation's coefficient within the first dimension. Nutraceutical parameters were less useful to describe a sample's trend since they were less correlated to dimension 1 and display a good correlation also with dimension 2. Dimension 2 probably represent slight dissimilarities among sample's trend under the assessment of nutraceutical variables while dimension 1 represents the common trend displayed by samples.

Proximity in the sets of data might indicate a resemblance among them (Pagès 2005). In this study, the proximity between texture and colour data sets might indicate that both sets shared a common pattern for all banana's samples, despite the presence of different single texture parameters with very different meanings under the

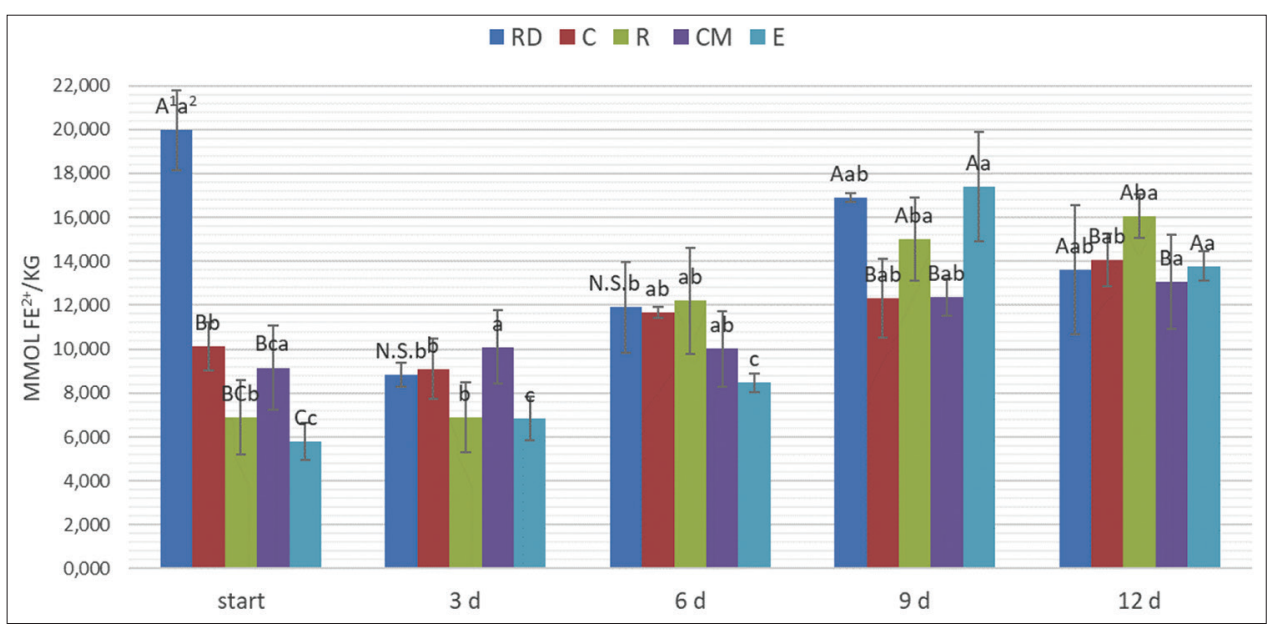

Fig 4. Antioxidant capacity values of Republic Dominican, Colombian, Costa Rica, Cameroon and Ecuador samples at $\mathrm{T} 1\left(21^{\circ} \mathrm{C}\right)$ storage conditions. 


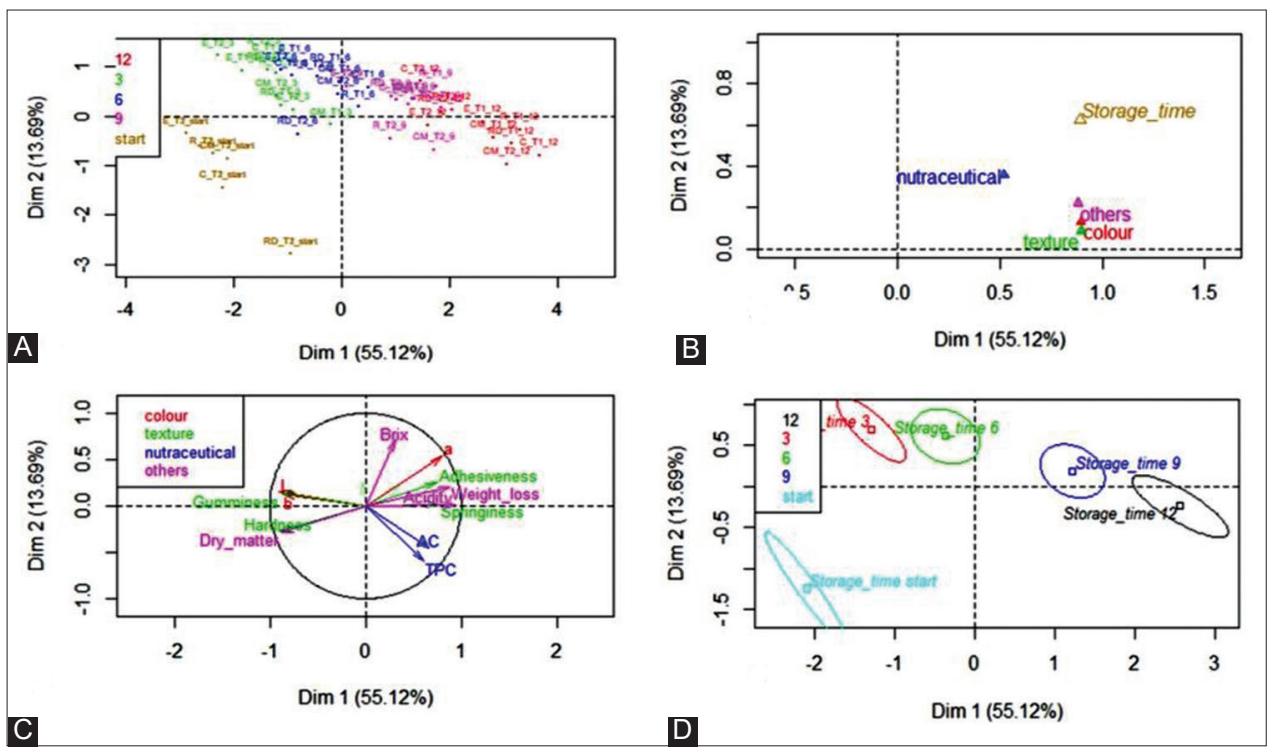

Fig 5. Multiple Factor Analysis. Biplot of the scores of dimensions 1 and 2 after analysis on quality evaluation attributes for all stored samples (A), contributions plot (B), circle of correlations of original variables (C) and confidence ellipses plotted (D).

global attribute texture. In addition to these results, in Fig. 5C it is also possible to see how parameters from texture and colour are more related among each other than parameters described in "others". In particular TSS (represented by "brix") displayed a different pattern if compared to weight loss and dry matter. TSS followed a non-linear trend during shelf life for all samples and the interaction of this parameter with weight loss and dry matter is only partially described due to the fact that the MFA common space is based on linear combinations of parameters (Mendes da Silva et al., 2019). Considering the distribution of single variables divided between negative and positive loadings in dimension 1, it can be concluded that all samples at the overripe stage (positive loadings) presented increased adhesiveness and springiness values, while fresh bananas (negative loadings) presented firm texture and higher gumminess values. These results are similar to the Finnegan et al., (2015b) trial for several fresh-cut fruits. In this study, increase of springiness was not expected since bananas tend to become mealy in the overripe stage. However, it's important to note that MFA, such as PCA, is an ordination and descriptive technique (Hervé et al., 2013), therefore, it's important to complement MFA results wit the univariate analysis to verify if they are reliable. Anova results showed there were no significant differences in springiness values during shelf life for almost all samples, with the exception of Colombia and Costa Rica samples at T2 conditions and only Colombia samples at T1 conditions. Thus, positive loading of springiness in the MFA plot is debatable.

Similar to PCA, sample's coordinates represent its relationship with dimensions and are called factor scores. These scores are used to plot observations that are represented as points on a map (Fig. 5A). Distances between points best reflect the similarities between the observations (Hervé et al., 2013, Finnegan and Beirne, 2015b). In this study, as expected, samples were mainly grouped by period of shelf life rather than origin, indicating a similar deterioration pattern for all samples along dimension 1, moving from dimensions of negative to positive values. However, differences among sample's patterns can still be observed: Dominican samples at day "start"were also better related to dimension 2, which was also positively related to nutraceutical variables. After day "start", Dominican samples presented a similar behaviour to the other samples, significantly losing nutraceutical properties as shown by Anova results. It's also important to note that Ecuador samples retained better quality overall since these samples presented lower loading values on dimension 1 during almost the entire period of storage, with exception of the " $9 \mathrm{~d}$ " period. By using the MFA, it is possible to apply confidence ellipses to data obtained through several repetitions (Dehlholm et al., 2012). Thus, this study was able to calculate confidence ellipses for data grouped by storage time in order to evaluate if there were significant global differences within samples. It is highlighted in Fig. 5D how significant differences were shown for all storage periods, with day "start" and the " $12 \mathrm{~d}$ " period presenting higher variability among samples. Higher variability on day "start" was expected since some parameters, such as nutraceutical analysis and $\mathrm{L}^{*}$ parameter, distinguished RD bananas from the rest of samples, while higher variability after 12 days was probably due to better quality retention of Ecuador samples. 


\section{CONCLUSIONS}

In this work study, it was possible to assess quality indicators and deterioration patterns of bananas from five different origins. Significant differences were found for most of the parameters analysed, suggesting that origin was a good determinant on quality attributes and shelf life. Although the shared variation displayed by the common behaviour of samples throughout the shelf life was highlighted bythe Multiple Factor Analysis (MFA) plots. Therefore, overall, it can be suggested that origin has a minor impact in the banana's deterioration patterns, even though for some parameters it is possible to detect a better quality retention of Ecuador samples during shelf life, while Cameroon samples demonstrated the opposite term. As expected, the MFA contribution plot demonstrated that nutraceutical quality was not a good indicator of deterioration of samples, such as texture and colour parameters. Among single quality parameters, hardness and gumminess were good indicators of freshness, along with colour parameters, such as $\mathrm{L}^{*}$ and $\mathrm{b}^{*}$, while is suggested TSS might not be useful to predict the ripening stage due to its non-linear trend. These results suggest that the MFA might be an effective way to evaluate quality deterioration throughout shelf life. Nevertheless, concerning origin's impact on final quality and stability, further studies on different seasons must be conducted.

\section{Disclosure statement}

No potential conflict of interest was reported by the authors.

\section{Author's contributions}

Cristiana Peano designed the research, collaborated in the literature review and checked results. Nicole Roberta Giuggioli and Thais Mendes Da Silva collected data, interpreted results and wrote the paper. All authors read and approved the final manuscript, analyzed the data and participated jointly to the discussion. All authors have read and approved the final manuscript.

\section{REFERENCES}

Aday, M. S. and C. Caner. 2013. The shelf life extension of fresh strawberries using an oxygen absorber in the biobased package. LWT Food Sci. Technol. 52: 102-109.

Adi, D. D., I. N. Oduro and C. Tortoe. 2019. Physicochemical changes in plantain during normal storage ripening. Sci. Afr. 6: e00164.

Anyasi, T. A., A. I. Jideani and G. A. Mchau. 2015. Morphological, physicochemical, and antioxidant profile of non commercial banana cultivars. Food Sci. Nutr. 3: 221-232.

Benzie, I. F. F. and J. J. Strain. 1996. The ferric reducing ability of plasma (FRAP) as a measure of "antioxidant power": The FRAP assay. Anal. Biochem. 239: 70-76.

Bicho, N. C., A. Leitão, E. Nio, J. C. Ramalho and F. C. Lidon. 2014.
Application of colour parameters for assessing the quality of arabica and robusta green coffee. Emirates J. Food Agric. 26: 9-17.

Caner, C., M. S. Aday and M. Demir. 2008. Extending the quality of fresh strawberries by equilibrium modified atmosphere packaging. Eur. Food Res. Technol. 227: 1575-1583.

Chauhan, O. P., P. S. Raju, D. K. Dasgupta and A. S. Bawa. 2006. Instrumental textural changes in banana (Var. Pachbale) during ripening under active and passive modified atmosphere. Int. J. Food Prop. 9: 237-253.

Ding, P., S. H. Ahmad, A. R. A. Razak, N. Saari and M. T. M. Mohamed. 2007. Plastid ultrastructure, chlorophyll contents, and colour expression during ripening of cavendish banana (Musa acuminata 'Williams') at $18^{\circ} \mathrm{C}$ and $27^{\circ} \mathrm{C}$. N. Z. J. Crop Hortic. Sci. 35: 201-210.

Esteban, V., V. Pablo, S. Luis de and A. Gastón. 2013. Evaluation of the sensory characteristics of strawberry cultivars throughout the harvest season using projective mapping. J. Sci. Food Agric. 94: 591-599.

Finnegan, E. and D. O Beirne. 2015a. Characterising deterioration patterns in fresh-cut fruit using principal component analysis II: Effects of ripeness stage, seasonality, processing and packaging. Postharvest Biol. Technol. 100: 91-98.

Finnegan, E. and D. O. Beirne. 2015b. Characterising and tracking deterioration patterns of fresh-cut fruit using principal component analysis-Part I. Postharvest Biol. Technol. 100: 73-80.

Gambetta, M. J., D. Cozzolino, E. S. Bastian and W. D. Jeffery. 2017. Exploring the effects of geographical origin on the chemical composition and quality grading of Vitis vinifera L. CV. Chardonnay Grapes. Molecules. 22: 218.

Giuggioli, N., R. Briano, P. Alvariza and C. Peano. 2018. Preliminary evaluation of day-neutral strawberry cultivars cultivated in Italy using a qualitative integrated approach. Hortic. Sci. 45: 29-36.

Hervé, A., J. W. Lynne and V. Domininique. 2013. Multiple factor analysis: Principal component analysis for multitable and multiblock data sets. Wiley Interdiscip. Rev. Comput. Stat. 5: 149-179.

Hewage, K. S., H. Wainwright and R. S. W. Wijeratnam. 1996. Quantitative assessment of chilling injury in bananas using a colorimeter. J Hortic. Sci. Biotechnol. 71: 135-139.

Huang, H., Q. Zhu, Z. Zhang, B. Yang and X. Duan. 2013. Effect of oxalic acid on antibrowning of banana (Musa spp, AAA group, cv. 'Brazil') fruit during storage. Sci. Hortic. 160: 208-212.

Johansson, E., A. Hussain, R. Kuktaite, S. C. Andersson and M. E. Olsson. 2014. Contribution of organically grown crops to human health. Int. J. Environ. Res. Public Health. 11: 3870-3893.

Kiyoshi, M. and W. Tanimura. 2003. Change of polyphenol compounds in banana pulp during ripening. Food Preserv. Sci. 29: 347-351.

Lassoued, N., J. Delarue, B. Launay and C. Michon. 2008. Baked product texture: Correlations between instrumental and sensory characterization using flash profyle. J. Cereal Sci. 48: 133-143.

Mendes Da Silva, T., C. Peano and N. R. Giuggioli. 2019. A novel statistical approach to assess the quality and commercial viability of a retail branded perishable fruit. CyTA J. Food. 17: 581-592.

Mendes da Silva, T., R. Briano, C. Peano and N. R. Giuggioli. 2020. The use of a new explanatory methodology to assess maturity and ripening indices for kiwiberry (Actinidia arguta): Preliminary results. Postharvest Biol. Technol. 163: 111122.

Nannyonga, S., S. Bakalis, J. Andrews, E. Mugampoza and K. Gkatzionis. 2016. Mathematical modelling of color, texture kinetics and sensory attributes characterisation of ripening 
bananas for waste critical point determination. J. Food Eng. 190: 205-210.

Nishinari, K. and Y. Fang. 2018. Perception and measurement of food texture-solid foods. J. Texture Stud. 49: 160-201.

Nyanjage, M. O., H. Wainwright, C. F. H. Bishop and F. J. Cullum. 2001. A comparative study on the ripening and mineral content of organically and conventionally grown Cavendish bananas. Biol. Agric. Hortic. 18: 221-234.

OECD Guideline. 2009. OECD Fruit and Vegetables Scheme. OECD, Paris.

Opara, U. L., R. Al-Yahyai, N. Al-Waili, F. Said, M. Al-Ani, A. Manickavasagan and A. Al-Mahdouri. 2013. Postharvest responses of 'Malindi' cavendish banana to various storage conditions. Int. J. Fruit Sci. 13: 373-388.

Pathare, P. B., U. L. Opara and F. A. J. Al-Said. 2013. Colour measurement and analysis in fresh and processed foods: a review. Food Bioprocess Technol. 6: 36-60.

Patel, K. N., R. B. Modi, H. G. Patel and K. D. Aparnathi. 2013. Browning, its chemistry and implications in dairy products: $A$ review. Indo Am. J. Agric. Vet. Sci. 1: 1-12.

Pranita, J., N. J. Shyam, P. K. Poonam, B. Rishi, K. S. Ashish and W. Vishakha. 2014. Prediction of textural attributes using color values of banana (Musa sapientum) during ripening. J. Food Sci. Technol. 51: 1179-1184.

Rajkumar, P., N. Wang, G. Eimasry, G. S. V. Raghavan and Y. Gariepy. 2012. Studies on banana fruit quality and maturity stages using hyperspectral image. J. Food Eng. 108: 194-200.

Sanaeifar, A., A. Bakhshipour and M. de la Guardia. 2016. Prediction of banana quality indices from color features using support vector regression. Talanta. 148: 54-61.

Singh, B., J. P. Singh, A. Kaur and N. Singh. 2016. Bioactive compounds in banana and their associated health benefits a review. Food Chem. 206: 1-11.

Slinkard, K. and V. L. Singleton. 1977. Total phenol analysis: Automation and comparison with manual methods. Am. J. Enol. Viticult. 28: 49-55.

Suna, S., C. E. Tamer, B. Incedayi, G. Ö. Sinir and Ö. Çopur. 2014. Impact of drying methods on physicochemical and sensory properties of apricot pestil. Indian J. Tradit. Knowl. 13: 47-55.

Taiti, C., C. Costa, P. Menesatti, S. Caparrotta, N. Bazihizina, E. Azzarello, W. A. Petrucci, E. Masi and E. Giordani. 2015. Use of volatile organic compounds and physicochemical parameters for monitoring the post-harvest ripening of imported tropical fruits. Eur. Food Res. Technol. 241: 91-102.

Thakker, J. N., P. Patel and P. C. Dhandhukia. 2011. Induction of defence-related enzymes in susceptible variety of banana: role of Fusarium derived elicitors. Arch. Phytopathol. Plant Prot. 44: 1976-1984.

Tsamo, V. P., C. M. Andre, C. Ritter, K.Tomekpe, G. N. Newilah, H. Rogez and Y. Larondelle. 2014. Characterization of Musa sp. Fruits and plantain banana ripening stages according to their physicochemical attributes. J. Agric. Food Chem. 62: 8705-8715.

Turner, D. W. 2001. Bananas and plantains. In: S. K. Mitra (Ed.), Postharvest Physiology and Storage of Tropical and Subtropical Fruit, CAB International, Wallingford, p. 47-83.

Ward, G. and A. Nussinovitch. 1996. Peel gloss as a potential indicator of banana ripeness. LWT Food Sci. Technol. 29: 289-294. 